Research report

\title{
Long-term effects of selective immunolesions of cholinergic neurons of the nucleus basalis magnocellularis on the ascending cholinergic pathways in the rat: A model for Alzheimer's disease
}

\author{
Csaba Szigeti ${ }^{a}$, Norbert Bencsik ${ }^{\mathrm{a}}$, Aurel Janos Simonka ${ }^{\mathrm{b}}$, Adam Legradi ${ }^{a}$, Peter Kasa ${ }^{\mathrm{c}}$, Karoly Gulya ${ }^{\mathrm{a}, *}$ \\ a Department of Cell Biology and Molecular Medicine, University of Szeged, Szeged, Hungary \\ ${ }^{\mathrm{b}}$ Department of Traumatology, University of Szeged, Szeged, Hungary

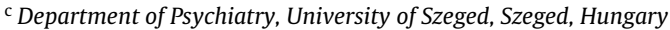

\section{A R T I C L E I N F O}

\section{Article history:}

Received 10 November 2012

Accepted 7 January 2013

Available online 26 January 2013

\section{Keywords:}

AChE

ChAT

Cholinergic cell loss

Cholinergic forebrain

Nucleus basalis magnocellularis

Saporin

\begin{abstract}
A B S T R A C T
Alzheimer's disease is associated with a significant decrease in the cholinergic input to the neocortex. In a rat model of this depletion, we analyzed the subsequent long-term changes in cholinergic fiber density in two well-defined areas of the frontal and parietal cortices: Fr1, the primary motor cortex, and HL, the hindlimb area of the somatosensory (parietal) cortex, two cortical cholinergic fields that receive inputs from the nucleus basalis magnocellularis (nBM). A specific cholinergic lesion was induced by the intraparenchymal injection of $192 \mathrm{IgG}$-saporin into the nBM. Choline acetyltransferase (ChAT) immunohistochemistry was applied to identify the loss of cholinergic neurons in the nBM, while acetylcholinesterase (AChE) enzyme histochemistry was used to analyze the decreases in the number of cholinoceptive neurons in the nBM and the cholinergic fiber density in the Fr1 and HL cortical areas in response to the nBM lesion. The immunotoxin differentially affected the number of ChAT- and AChE-positive neurons in the nBM. 192 IgG-saporin induced a massive, irreversible depletion of the ChAT-positive (cholinergic) neurons (to $11.7 \%$ of the control level), accompanied by a less dramatic, but similarly persistent loss of the AChE-positive (cholinoceptive) neurons (to $59.2 \%$ of the control value) in the nBM within 2 weeks after the lesion. The difference seen in the depletion of ChAT- and AChE-positive neurons is due to the specificity of the immunotoxin to cholinergic neurons. The cholinergic fiber densities in cortical areas Fr1 and HL remained similarly decreased (to $62 \%$ and $68 \%$ of the control values, respectively) up to 20 weeks. No significant rebound in AChE activity occurred either in the nBM or in the cortices during the period investigated. This study therefore demonstrated that, similarly to the very extensive reduction in the number of ChAT-positive neurons in the nBM, cortical areas Fr1 and HL underwent long-lasting reductions in the number of AChE-positive fibers in response to specific cholinergic lesioning of the nBM.
\end{abstract}

(C) 2013 Elsevier Inc. All rights reserved.

\section{Introduction}

The cholinergic basal forebrain, one of the diffusely projecting systems of the brain, comprising of the cholinergic neurons in the medial septum, the vertical and horizontal limbs of the diagonal band of Broca and the nucleus basalis magnocellularis (nBM), provides widespread innervation to the neocortex (Baxter and Chiba, 1999; Fitz et al., 2008; Kasa, 1986; Kasa et al., 1997; Kilgard and Merzenich, 1998; Wrenn and Wiley, 1998). The nBM receives inputs from limbic and paralimbic structures and sends projections

\footnotetext{
* Corresponding author at: Department of Cell Biology and Molecular Medicine, University of Szeged, 4 Somogyi u., Szeged H-6720, Hungary. Tel.: +36 62544 570; fax: +36 62544569 .

E-mail address: gulyak@bio.u-szeged.hu (K. Gulya).
}

to the entire cortex (Mesulam et al., 1983). Degeneration of the nBM gives rise to a number of profound morphological, biochemical and functional effects directly related to the development of Alzheimer's disease (AD). The involvement of the cholinergic system in AD has been documented extensively (Cuello et al., 2010; Kasa et al., 1997; Mufson et al., 2008). The observation of the loss of cholinergic neurons in the nBM, associated with a decreased level of cortical cholinergic innervation and leading to the symptoms characteristic of $\mathrm{AD}$, has stimulated the development of animal models involving a variety of techniques for lesioning of the nBM (BergerSweeney et al., 1994, 2001; Mallet et al., 1995; Mohapel et al., 2005; Wenk et al., 1994).

The introduction of the use of 192 IgG-saporin, a highly specific cholinergic immunotoxin, improved the specificity of these studies (Book et al., 1994; Fitz et al., 2008; Wiley et al., 1991). This immunotoxin consists of the monoclonal antibody 
192 IgG, disulfide-coupled to saporin, a member of the ribosomeinactivating protein family derived from the plant Saponaria officinalis. The antibody component is directed against rat p75, a low-affinity neurotrophin receptor protein, which ensures the specificity of the toxin since only the cholinergic neurons express p75 in the nBM (Cuello et al., 1990). Following receptor binding and internalization, saporin enzymatically inactivates the large ribosomal subunit, thereby blocking protein synthesis and ultimately resulting in cell death; the neurodegenerative process can be considered complete in about 2 weeks (Wrenn and Wiley, 1998). Its specificity makes 192 IgG-saporin a useful agent with which to establish specific cholinergic lesions modeling the AD-associated cholinergic hypofunction. Although deficits in cholinergic function following several types of lesions to the nBM are well documented (Harati et al., 2008; Nag et al., 2009; Pizzo et al., 1999), there have been only a few reports regarding the time course of the development of this cholinergic hypofunction or its potential recovery (Abdulla et al., 1997; Höhmann and Coyle, 1988; Perry et al., 2001; Rossner et al., 1995a,b). Our present goal was therefore to demonstrate the persistence of a $192 \mathrm{IgG}$-saporin-induced lesion in the $\mathrm{nBM}$ and the long-term cortical response to this selective cholinergic neuron loss in architectonically well-defined frontal and parietal cortical projection areas. Choline acetyltransferase (ChAT, EC 2.3.1.6) immunohistochemistry and acetylcholinesterase (AChE, EC 3.1.1.7) enzyme histochemistry were used to assess the losses in the number of cholinergic and cholinoceptive neurons, respectively, and the degree of cortical cholinergic innervation. ChAT-positive neurons were considered cholinergic, while AChEpositive neurons were considered cholinoceptive only as AChE activity is also a common, but not obligatory, feature of most cholinergic neurons (Butcher, 1995; Butcher and Woolf, 1984).

\section{Materials and methods}

\subsection{Animals}

The experimental procedures were carried out in strict compliance with the European Communities Directive 86/609/EEC, and followed the Hungarian legislation requirements (XXVIII/1998 and 243/1998) and the University guidelines regarding the care and use of laboratory animals. The experimental protocols involving the participation of animals were approved by the Institutional Animal Welfare Committee of the University of Szeged (I-74-II/2009/MÁB). Adult (150-180 g) male Sprague-Dawley rats were obtained from the animal facility of the University. They were maintained in-house under standard housing conditions (alone in their cages) and kept on a normal diet and tap water ad libitum with a 12-h light cycle (lights on at 7:00 a.m.).

\subsection{Stereotaxic surgery and immunotoxin injection}

Animals were deeply anesthetized with chloral hydrate $(400 \mathrm{mg} / \mathrm{kg}$, i.p., Reanal, Hungary) and placed in a stereotaxic frame (Kopf Instruments, Tujunga, CA, USA) with the incisor bar set $3.5 \mathrm{~mm}$ below the interaural line. A surgical incision was made into the skin overlying the bregma and the scalp was pulled back with surgical clips. With a dental drill, a hole was made through the skull and a Hamilton syringe was lowered through this hole into the caudal portion of the nBM of the basal forebrain at the following coordinates (from the bregma): AP $-2.8 \mathrm{~mm}, \mathrm{ML}$ $+3.8 \mathrm{~mm}$, DV $-7.2 \mathrm{~mm}$, according to the stereotaxic atlas of Paxinos and Watson (2007). Control animals received $0.5 \mu \mathrm{l}$ of $0.1 \mathrm{M}$ phosphate-buffered saline (PBS) solution $\left(810 \mathrm{ml}\right.$ of $0.1 \mathrm{M} \mathrm{Na}_{2} \mathrm{HPO}_{4}$ and $190 \mathrm{ml}$ of $0.1 \mathrm{M} \mathrm{NaH}_{2} \mathrm{PO}_{4}$ in $0.9 \% \mathrm{NaCl}$; pH 7.4), while treated animals received $0.5 \mu \mathrm{l}$ of $192 \mathrm{IgG}$-saporin $(0.150 \mu \mathrm{g}$ in $1 \mu \mathrm{l}$ of 0.1 M PBS; Chemicon, Temecula, CA, USA). The immunotoxin or PBS solution was pressure-injected over a period of $5 \mathrm{~min}$. The needle was left in place for an additional $5 \mathrm{~min}$ after the injection. The injection site, its tissue environment and the investigated cortical projection areas of the nBM are depicted in Fig. 1.

\subsection{Tissue handling}

Two, $4,8,12$ or 20 weeks after the intranuclear injection into the nBM, the animals were deeply anesthetized and perfused transcardially with $150 \mathrm{ml}$ of $0.1 \mathrm{M}$ PBS, followed by $300 \mathrm{ml}$ of $4 \%$ formaldehyde in $0.1 \mathrm{M}$ PBS, pH 7.4. The brains were

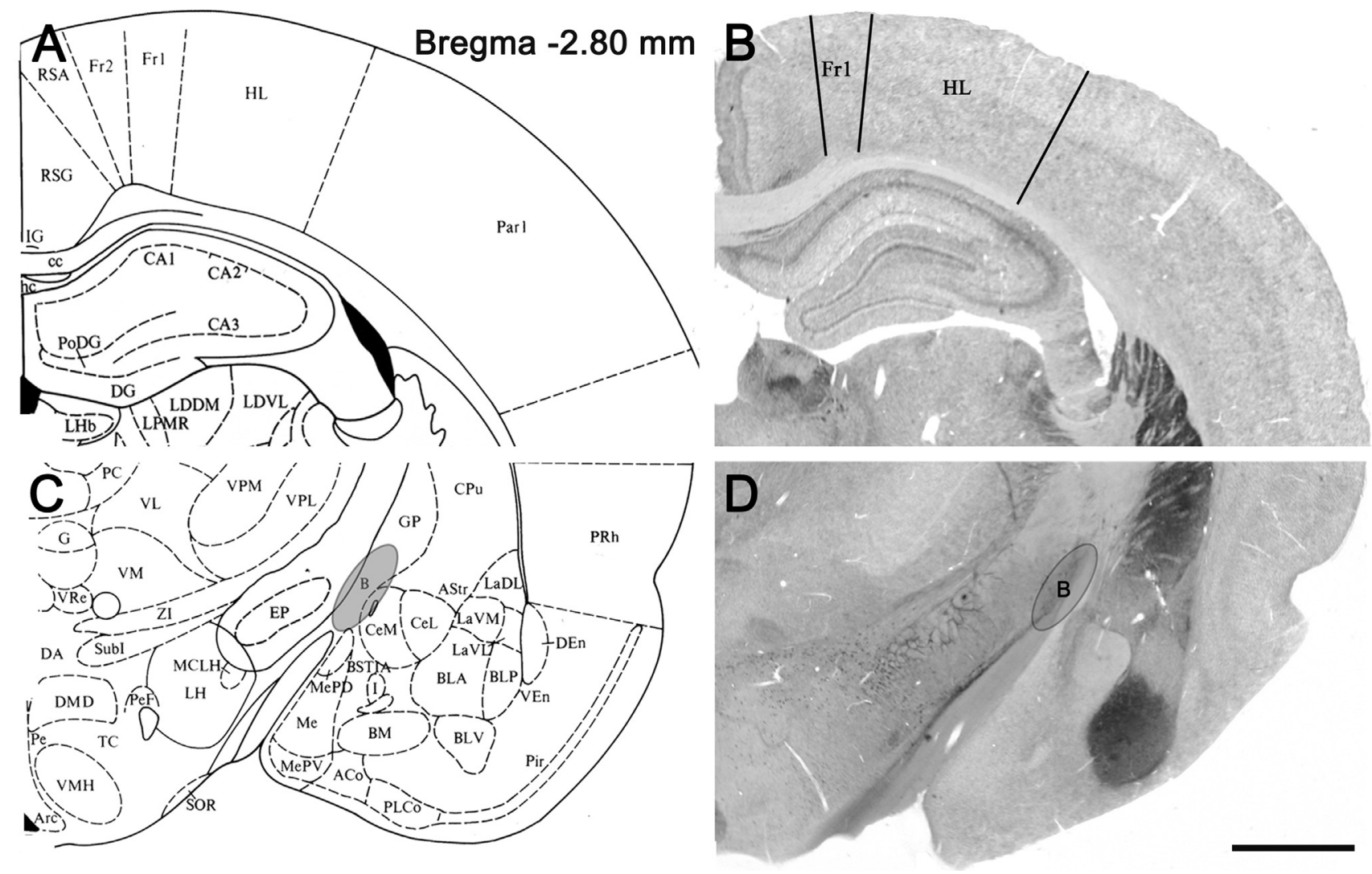

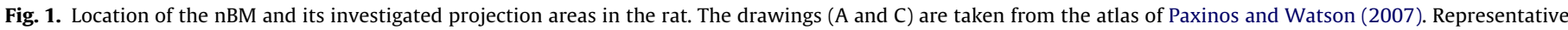

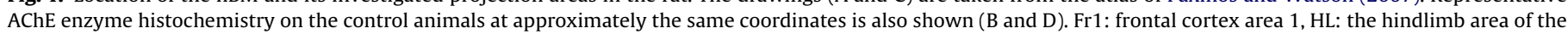
somatosensory cortex (according to the nomenclature of Zilles and Wree, 1995). The ellipse marked with B (in both C and D panels) denotes the nBM. Scale bar: $500 \mu \mathrm{m}$. 

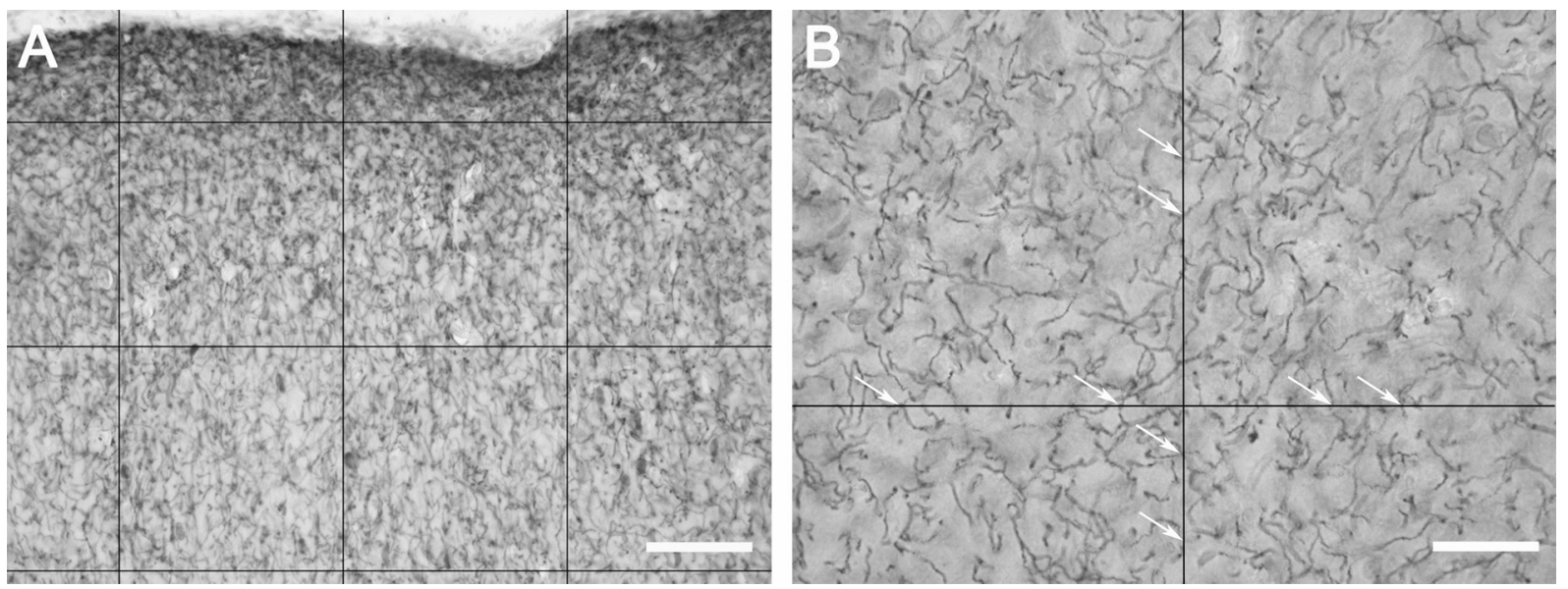

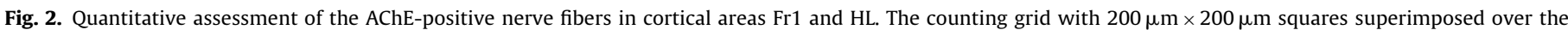
control Fr1 micrograph (A). The fibers crossing the gridlines (B, white arrows) were counted. Scale bars: $50 \mu \mathrm{m}$ (A) and $25 \mu \mathrm{m}$ (B).

removed, post-fixed in the same fixative for $4 \mathrm{~h}$, cryoprotected in $30 \%$ sucrose solution for $12 \mathrm{~h}$ and embedded in cryomatrix (Shandon Scientific Ltd., Pittsburg, PA, USA). Twenty- $\mu \mathrm{m}$-thick serial coronal sections were cut on a cryostat (Shandon $620 \mathrm{M}$; Anglia Scientific Instruments Ltd., Cambridge, UK), mounted on gelatincoated slides and processed for enzyme histochemistry and immunohistochemistry. To assess the damage, induced by 192 IgG-saporin injection into the nBM, architectonically well-defined areas from the frontal and parietal cortical areas (Fr1 and HL, according to the nomenclature of Zilles and Wree, 1995) in the ascending cortical cholinergic pathway were selected for quantitative ChAT immunohistochemistry and AChE enzyme histochemistry. The quantitative analysis of the AChE-positive ascending cholinergic fibers involved the entire Fr1 area (the primary motor cortex), whereas for the HL area, the region proximal to the median-sagittal axis of the primary somatosensory cortex was used.

\subsection{ChAT immunohistochemistry}

Cholinergic neurons were visualized by light microscopic fluorescent immunohistochemistry. Following permeabilization and blocking in $0.05 \mathrm{M}$ PBS containing $1 \%$ bovine serum albumin, $5 \%$ normal goat serum and $1 \%$ Triton X-100 for 30 min at $37^{\circ} \mathrm{C}$, ChAT immunoreactivity was visualized by incubating the sections overnight at $4{ }^{\circ} \mathrm{C}$ in the same buffer containing rabbit anti-ChAT primary antibody $(1: 200$, Chemicon, Temecula, CA, USA). After incubation with Alexa fluor 568-labeled goat anti-rabbit secondary antibody (1:1000; Invitrogen, Carlsbad, CA, USA) for $3 \mathrm{~h}$ at room temperature (RT) in the dark, nucleus staining was carried out with $1.5 \mathrm{ml}$ of Hoechst 33258 dye (Sigma, St. Louis, MO, USA) dissolved in $3 \mathrm{ml}$ of $1 \mathrm{mg} / \mathrm{ml}$ polyvinylpyrrolidone in $0.1 \mathrm{M}$ PBS. The tissue sections were dehydrated, covered with Vectashield (Vector Laboratories, Burlingame, CA, USA) and investigated under an epifluorescent microscope (Nikon Microphot FXA; Nikon, Tokyo, Japan).

\subsection{AChE enzyme histochemistry}

For the demonstration of cholinoceptive neurons in the $\mathrm{nBM}$ and AChE-positive fibers in the cortices Fr1 and $\mathrm{HL}, 30$ - $\mu$ m-thick free-floating coronal sections were collected in $0.1 \mathrm{M}$ sodium acetate buffer ( $\mathrm{pH} 7.4$ ). AChE-positive cells in the nBM were identified by a modified method of Koelle and Friedenwald (1949). Briefly, sections were incubated in $0.1 \mathrm{M}$ sodium acetate buffer ( $\mathrm{pH} 5.0$ ) containing $0.072 \mathrm{mg} / \mathrm{ml}$ of ethopropazine, $0.075 \mathrm{~g}$ of glycine, $0.05 \mathrm{~g}$ of $\mathrm{CuSO}_{4}$ and $0.12 \mathrm{~g}$ of acetylthiocholine iodide for $4 \mathrm{~h}$ in the dark with gentle agitation on a rotating platform. Enzymatic reactions were visualized in $4 \% \mathrm{Na}_{2} \mathrm{~S}$ in $0.1 \mathrm{M}$ sodium acetate buffer ( $\mathrm{pH} 5.0$ ) for $30 \mathrm{~min}$ in the dark. Sections were mounted, dehydrated and covered with di- $n$-butyl phthalate in xylene (DPX; Fluka, Buchs, Switzerland) and investigated under a light microscope.

In order to visualize the fine network of cholinergic fibers in the cortex, we used the rapid Martucciello method (Martucciello et al., 2001). Briefly, sections were immersed into the incubation medium $(0.1 \mathrm{M}$ acetate buffer, $0.1 \mathrm{M}$ sodium citrate, $5 \mathrm{mg} / \mathrm{ml}$ of acetylthiocholine iodide, $4 \mathrm{mM}$ ethopropazine, $30 \mathrm{mM} \mathrm{CuSO}_{4}$, freshly made $5 \mathrm{mM} \mathrm{K}_{3} \mathrm{Fe}(\mathrm{CN})_{6}$; $\mathrm{pH} \mathrm{6.0)}$ for $1 \mathrm{~h}$ at RT. After a brief rinse in $0.1 \mathrm{M}$ PBS, the sections were developed with SIGMAFAST DAB with a metal enhancer (Sigma) for 5 min at RT. Sections were mounted, covered with glycerine/0.05 M PBS (3:1) and investigated under a light microscope.

\subsection{Morphometry and statistical analysis}

Representative microphotographs from the nBM and cortical areas Fr1 and HL were taken with a digital microscope camera (Qimaging MicroPublisher 3.3 RTV, Qimaging Inc., Surrey, BC, Canada) attached to a Leica DMLB microscope
(Leica Mikroskopie und Systeme GmbH, Wetzlar, Germany). Fluorescently labeled cells were captured with a Spot camera (SPOT RT/ke, Diagnostic Instruments, Inc., Sterling Heights, MI, USA) on a Nikon Microphot FXA epifluorescent microscope (Nikon, Tokyo, Japan). Image processing was achieved with QCapturePro 6.2 for Windows (Qimaging Inc.) and SPOT Advanced software (Diagnostic Instruments, Inc.). ChAT-immunopositive neurons and cells positive for AChE histochemistry in the nBM were identified in alternating consecutive sections of each of the 3 rats from both the control (saline-lesioned) and the 192 IgG-saporin-lesioned groups. Labeled cells were counted with the use of Imagej, a public domain image processing and analysis program (version 1.38; developed at the U.S. National Institutes of Health by W. Rasband, and available from the Internet at http://rsb.info.nih.gov/ij).

To quantify the extents of the consequences of the nBM lesions in cortical areas $\mathrm{Fr} 1$ and $\mathrm{HL}, \mathrm{AChE}$-positive fibers were counted according to previously published methods (Kim et al., 2005; Stichel and Singer, 1987). Briefly, a $3 \times 3$ counting grid consisting of $200 \mu \mathrm{m}$ squares for a total of $600 \mu \mathrm{m} \times 600 \mu \mathrm{m}$ was superimposed over the entire depths of cortices Fr1 and HL ipsilateral to the injection and perpendicular to the pial surface. The density of AChE positive fibers was counted at a magnification of $100 \times$ and expressed as the number of fibers crossing the counting grid (Fig. 2) and compared across groups. For each animal, counts were made in 3 non-overlapping but adjacent fields of view in 3 consecutive brain sections, and averaged across the samples. Statistical analyses were carried out with SigmaStat 3.11 (Systat Software Inc., Chicago, IL, USA), a statistical software package using ANOVA and the Holm-Sidak method for post hoc comparisons. Data are reported as mean \pm S.D. Changes were considered significant at $p<0.05$.

\section{Results}

The effects of intraparenchymal 192 IgG-saporin injection into the caudal part of the nBM were demonstrated by using the cholinergic and cholinoceptive markers ChAT and AChE, respectively (Fig. 3). The immunotoxin differentially affected ChAT- and AChEpositive neurons in the nBM. The numbers of ChAT-expressing neurons and AChE-positive cell somata in the nBM of the salineinjected animals (Fig. $3 \mathrm{~A}$ and $\mathrm{C}$, respectively) were markedly reduced 2 weeks after the lesion elicited by 192 IgG-saporin injection (Fig. 3B and D for ChAT- and AChE-positive cells, respectively). The numbers of ChAT-positive cells in the nBM of the saline- and the toxin-injected animals were $196 \pm 0.8$ and $23 \pm 1.7$, respectively. Thus, 192 IgG-saporin had depleted the number of ChAT-expressing neurons in the nBM to $11.7 \%$ of the control level by 2 weeks after the injection (Fig. 4A). There was no significant change observed in the number of ChAT-positive neurons up to 20 weeks postlesion (data not shown). The number of AChE-positive cell somata in the nBM of the saline-injected animals $(24.0 \pm 1.9)$ had decreased less dramatically, to $59.2 \%$ of the control level $(14.0 \pm 1)$, by 2 weeks after the saporin injection. The reduction was maintained at $4(13.0 \pm 3.7)$, $8(12.6 \pm 1.3), 12(14.0 \pm 1.4)$ and $20(15.1 \pm 0.2)$ weeks after the immunotoxin injection (Fig. 4B). 

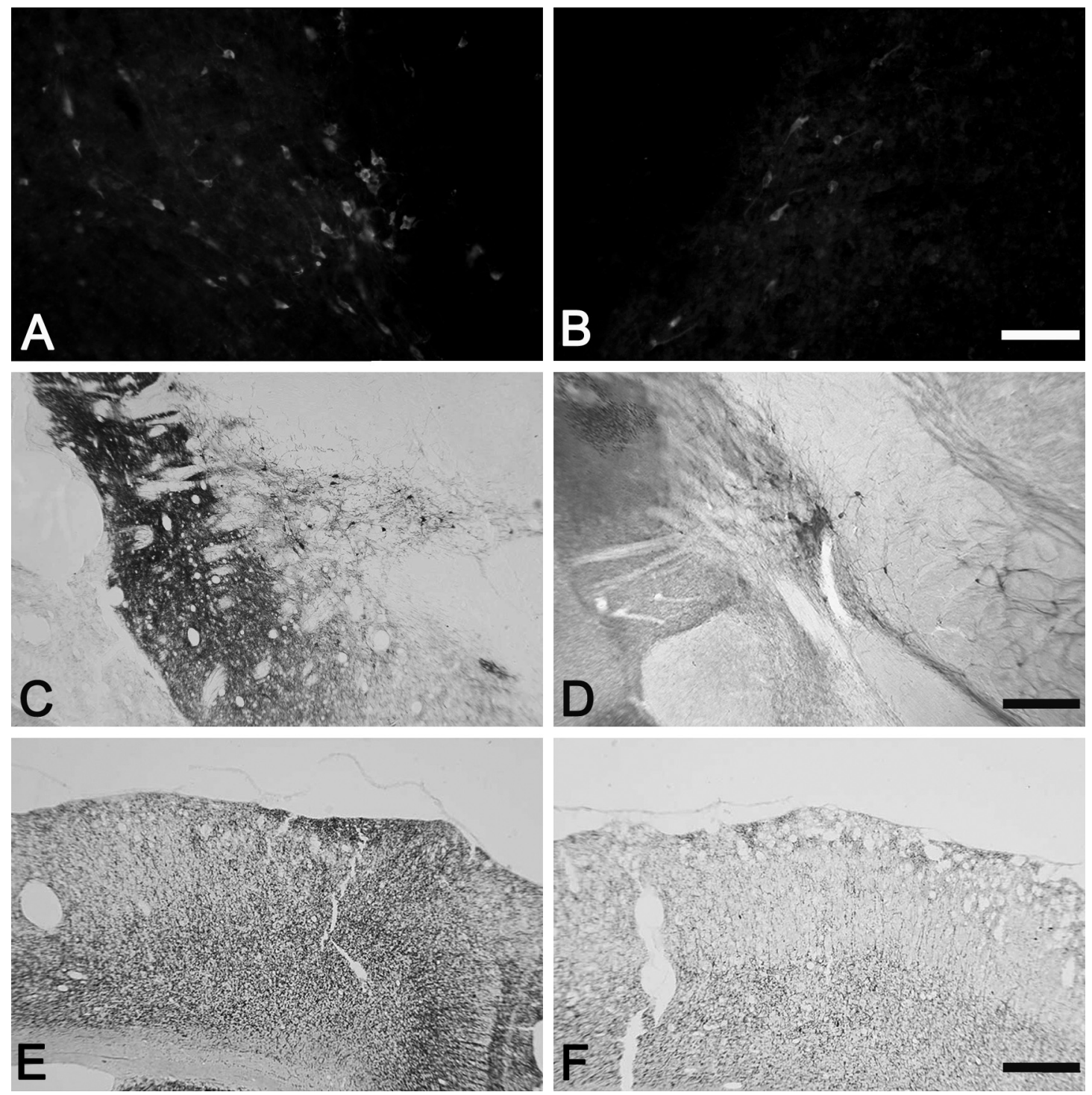

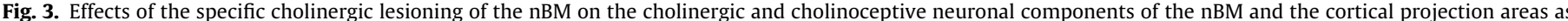

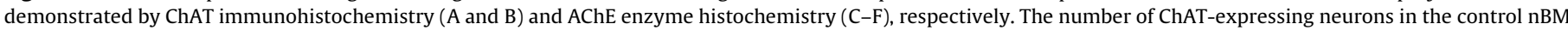

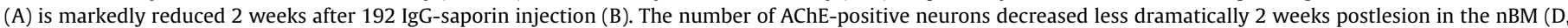

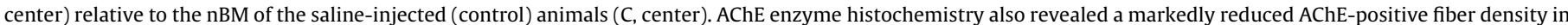

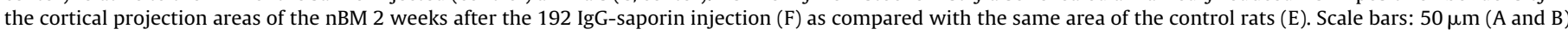
and $100 \mu \mathrm{m}(\mathrm{C}-\mathrm{F})$

The lesion-induced reductions in the cholinergic fiber density of the cortical projection areas of the $\mathrm{nBM}$ are demonstrated in Fig. 3E and F. The cortical AChE-positive fiber densities in areas Fr1 and HL (Fig. 5A and C) of the control (saline-injected) animals were $170.0 \pm 7.5$ and $186.15 \pm 6$, respectively. The 192 IgG-saporinelicited specific cholinergic lesion resulted in similarly significant reductions in the AChE-positive fiber density (Fig. 5B and D). The extent of these reductions was very similar in both cortical regions at all survival times investigated (Fig. 6). For example, at 2 weeks after the injection of 192 IgG-saporin into the nBM, the number of AChE-positive fibers in cortical area $\mathrm{Fr} 1$ was $76.5 \%$ of the control value $(130.5 \pm 2)$. At 4 weeks after the lesion, the number was further decreased to $67 \%$ of the control value $(114.6 \pm 1.4)$, and it reached its minimum at 12 weeks $(112.5 \pm 9.6 ; 65 \%$ of the control). In cortical area $\mathrm{HL}$, the number of AChE-positive fibers at 2 weeks after the lesion was $68 \%$ of the control value $(128.0 \pm 1.9)$; the minimum $(116.9 \pm 2.4)$ was attained at 4 weeks postlesion $(62 \%$ of the control value).

\section{Discussion}

Small animal models are essential in understanding the pathomechanism underlying neurodegenerative disorders (Brooks et al., 2012; Hall and Roberson, 2012). Several animal studies have established that selective lesioning of the cholinergic system produced alterations similar to that seen in AD (Abdulla et al., 1997; Berger-Sweeney et al., 2001; Fitz et al., 2008; Leanza et al., 1995). The possibility of achieving selective induction of the degeneration of cholinergic neurons in certain basal forebrain structures in rodents led to the development of animal models that mimic many biochemical, neuroanatomical and behavioral aspects of AD (Galani et al., 2002; Leanza et al., 1995; Rossner et al., 1995b; Walsh et al., 1995). Although the administration of the potent neurotoxin 192 IgG-saporin to rats does not produce all of the pathological features of $\mathrm{AD}$ (e.g., behavioral; Wenk et al., 1994), its specific and permanent cholinergic cell destruction does provide a reliable animal model with which to test hypotheses 

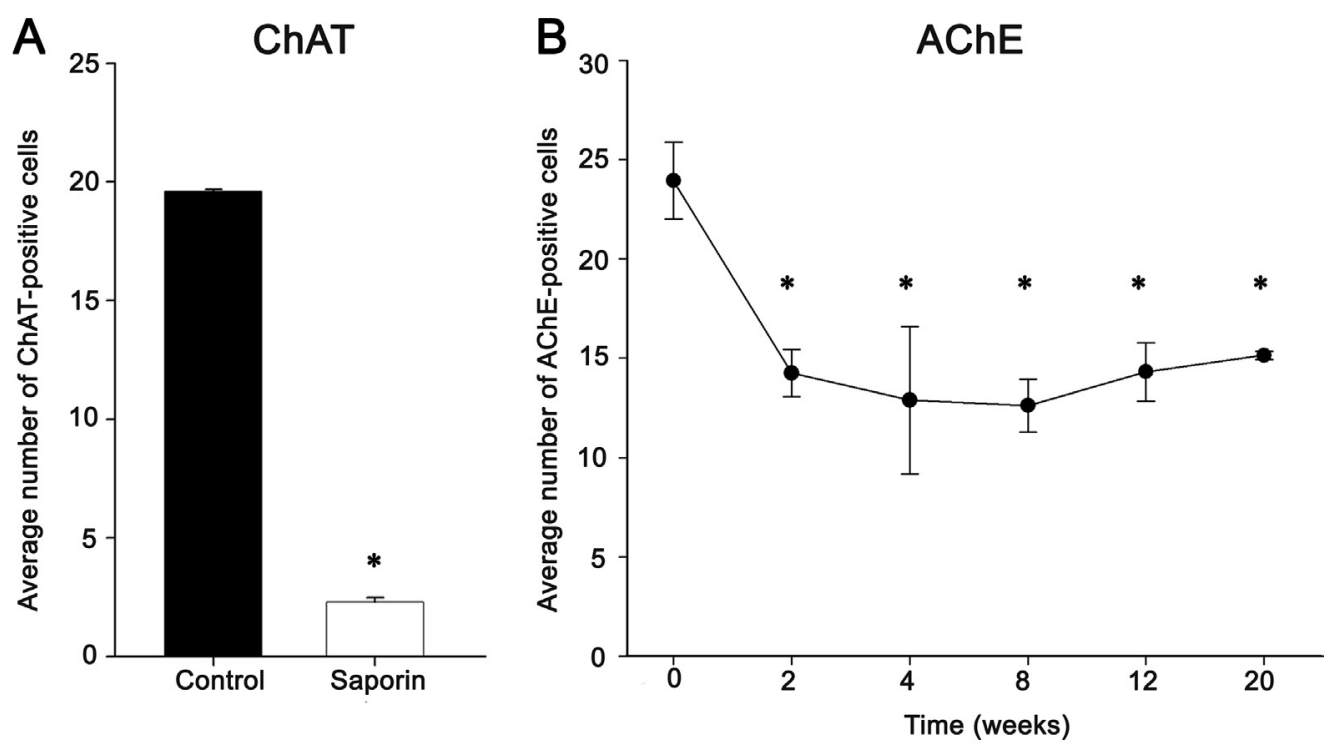

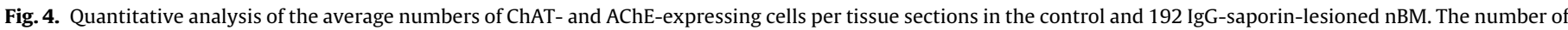

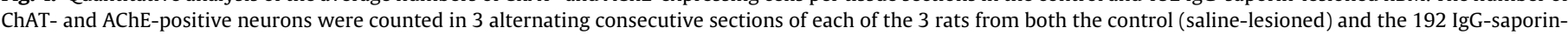

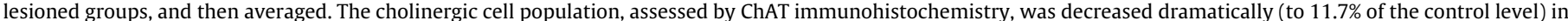

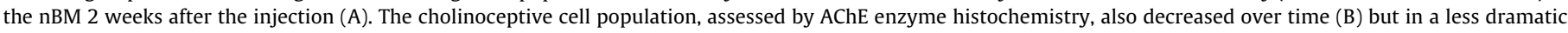

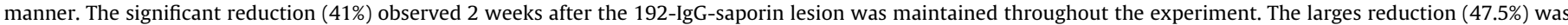

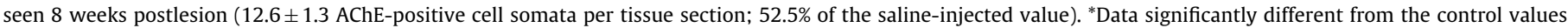
$(p<0.05 ;$ ANOVA).
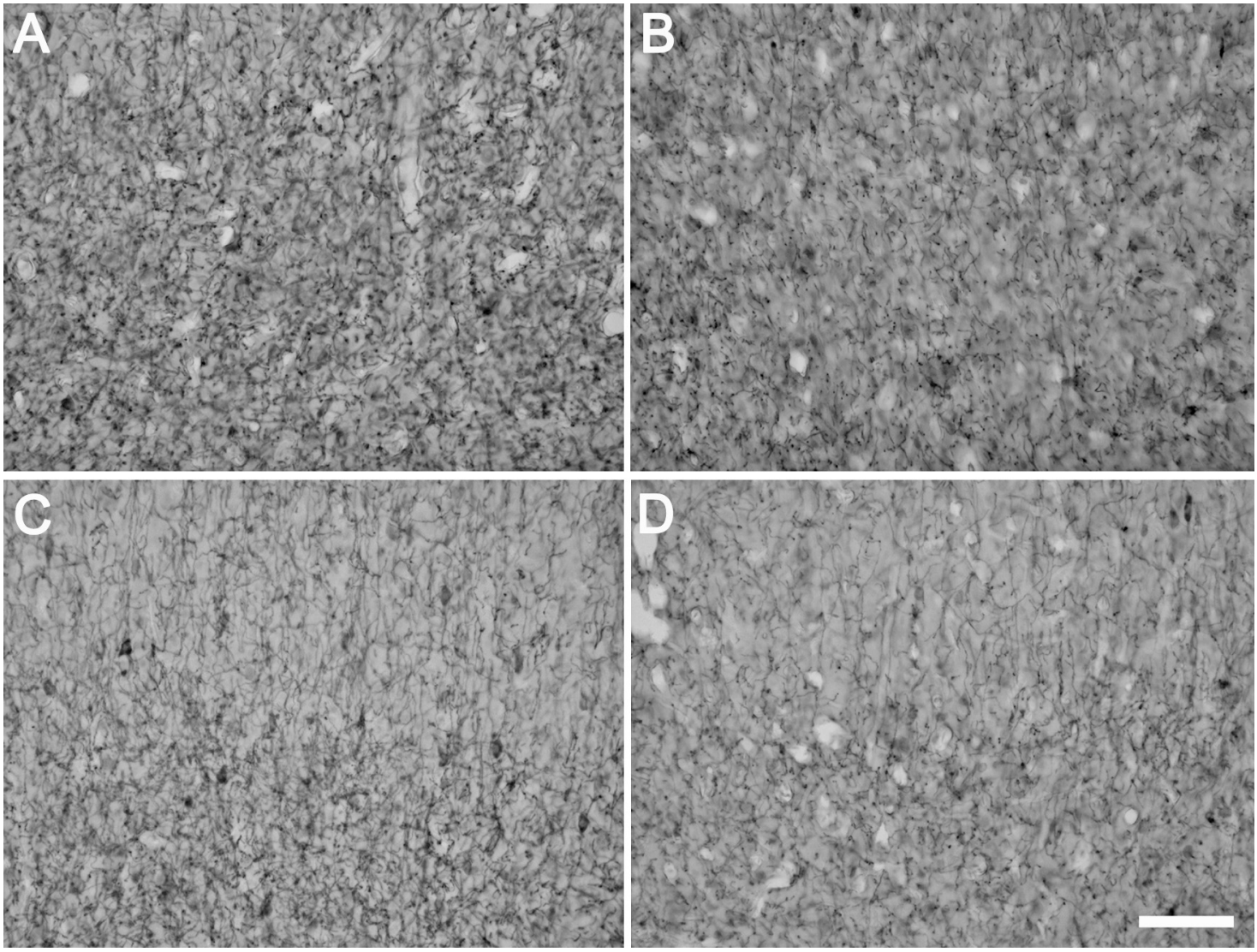

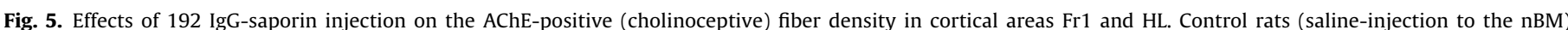

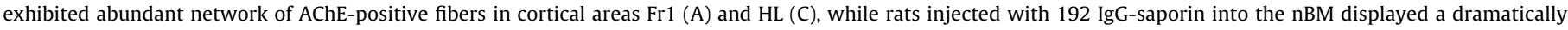
reduced AChE-positive network in the cortical areas Fr1 (B) and HL (D) 20 weeks after the injection. Scale bar: $100 \mu \mathrm{m}$. 


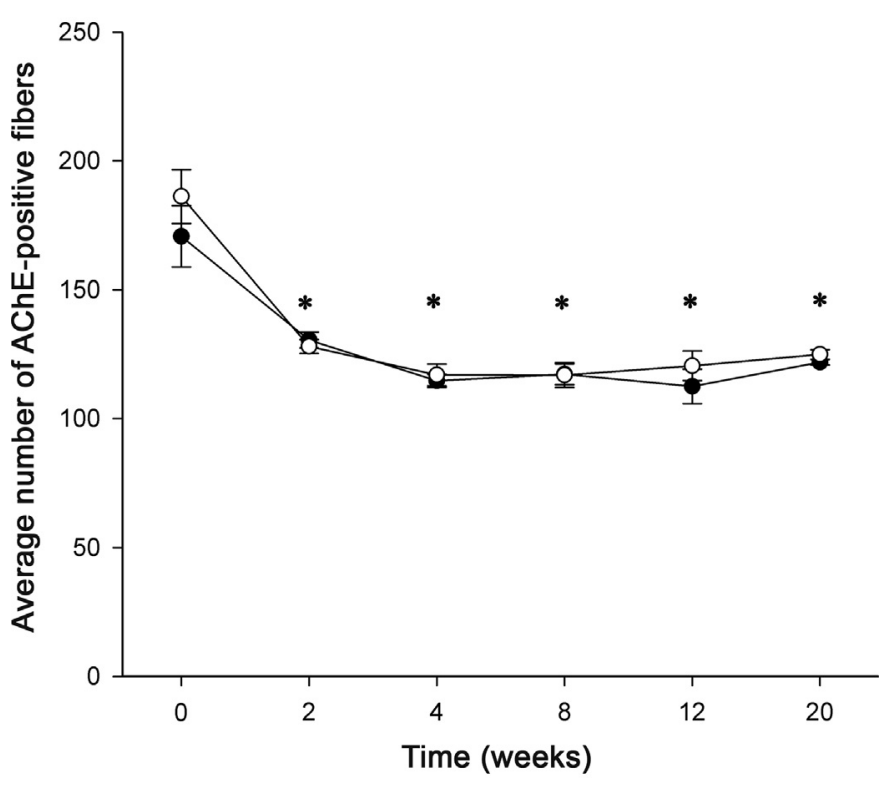

Fig. 6. Time course of changes in the average numbers of AChE-positive (cholinoceptive) fibers in the whole depths of the cortical areas Fr1 (filled circles) and HL (empty circles) after 192 IgG-saporin lesion of the nBM. The number of fibers crossing the counting grid (described in Materials and methods) was counted in the whole depth of the cortices in 3 non-overlapping but adjacent fields of view in 3 consecutive sections of 3 rats, and averaged. Note the persistent reduction in cholinergic fiber density in both cortical areas, with no noticeable rebound at any time during the study. *Data significantly different from the control values ( $p<0.05$; ANOVA).

relating to the pathogenesis of AD (Fitz et al., 2008; Wiley et al., 1995).

The present study demonstrated that 192 IgG-saporin induced dramatic and permanent decreases in the numbers of ChAT- and AChE-positive neurons in the nBM 2 weeks after its unilateral injection into the nBM, and caused significant, long-lasting decreases in the densities of AChE-positive fibers in cortices Fr1 and HL of adult rats. A similar cholinergic fiber depletion in the human neocortex is one of the characteristic features of $\mathrm{AD}$ (Geula and Mesulam, 1989). The intranuclear injection of 192 IgG-saporin into the nBM destroyed nearly $90 \%$ of the ChAT-positive neurons but only about half (41\%) of the AChE-positive neuronal somata in the nBM. The discrepancy in the number of affected neurons indicates that not only cholinergic neurons are cholinoceptive (AChE-positive) in the nBM, but there are other neuronal populations here also that express AChE. Some of these AChEpositive neurons are resistant to the immunolesion because they do not have $\mathrm{p75}$, the low-affinity neurotrophin receptor protein that ensures the specificity of the toxin to bind to and eventually kill the cholinergic neurons. Thus, the difference seen between the number of destroyed ChAT- and AChE-positive neurons is due to the specific binding of 192 IgG-saporin to the cholinergic (e.g., ChAT-positive) but not to the cholinoceptive (e.g., AChE-positive) neurons.

The topographical distribution of cholinergic neuronal cell bodies has been extensively studied in the rat CNS by ChAT immunohistochemistry and AChE histo- and immunohistochemistry. Although the correspondence, both in terms of distribution and morphology, between ChAT-containing and AChE-positive neurons in most regions of the CNS is generally good, there are a number of brain areas where these biomarkers do not label the same cell (Satoh et al., 1983), e.g., the AChE-positive cells are not necessarily ChAT-positive. Thus, AChE as a biomarker could not exclusively be used to detect cholinergic neurons after the immunolesion in the nBM. Moreover, the subcellular distribution of AChE in the principal cholinergic neurons of the brain generally follows a characteristic pattern which is different from that of AChE-positive non-cholinergic neurons (Henderson, 1989).

Albeit some of the previous studies had similar results to that of our present study, they were in many instances designed differently as the number of biomarkers tested (both at the site of the lesion and the projection areas), the route of administration, the amount of immunotoxin used or the postlesion time was concerned. For example, a single intracerebroventricular (i.c.v.) injection of 192 IgG-saporin into the caudal part of the nBM was earlier reported to result in a similarly irreversible and virtually complete depletion in the number of ChAT-expressing neurons in this brain area (Leanza et al., 1995), and to cause neurochemical alterations in the hypothalamus and cortical areas that typically reflect a cholinergic hypofunction (Rossner et al., 1995b). 192 IgG-saporin was also tested in lesioning other cholinergic components of the rat brain. When injected i.c.v., the immunotoxin also selectively lesioned the septal cholinergic neurons, resulting in consistently and significantly decreased AChE-positive fiber densities in various cortical regions (Galani et al., 2002).

The cortical areas have extensive cholinergic innervation (Butcher, 1995; Mesulam et al., 1983). We studied two cholinergic terminal fields with different functions after immunolesion to the nBM. The cortical area Fr1 is part of the motor cortex in the rat and has afferentation not only from the cholinergic forebrain, but also from a wide range of other cerebral nuclei (Mesulam et al., 1983; Zilles and Wree, 1995). Fr1 also has reciprocal connections with the ipsi- and contralateral HL regions that are part of the primary somatosensory cortex (Zilles and Wree, 1995). It must be emphasized, however, that these cortices retain a substantial proportion of the cortical cholinergic fibers after destruction of the ChAT-positive neurons in the nBM as they provide approximately half of the cholinergic inputs into the neocortex and amygdala (Wrenn and Wiley, 1998). Apart from the extrinsic sources of the cholinergic fibers, cholinergic neurons intrinsic to the cortex have also been indentified (see Lysakowsky et al., 1989, for further references); this population can account for $30 \%$ or less of the cortical cholinergic innervation (Johnson et al., 1981), and is not affected by the immunolesion of the nBM.

In human $\mathrm{AD}$ brains, the numbers of $\mathrm{AChE}$-positive cortical fibers are significantly reduced in the frontal, parietal, temporal and visual cortices (Geula and Mesulam, 1989; Ridley et al., 2005). The selective lesioning of nBM-derived cholinergic inputs affected both motor and sensory functions associated with cortical areas Fr1 and HL as our results from the saporin-induced animal model of $A D$ revealed significant reductions in the Fr1 and HL cortical AChE-positive fiber networks. The patterns of these reductions were similar in these two cortical areas. The reduction of the AChE-positive fibers in cortical areas Fr1 and HL were long-lasting: we did not identify any subsequent significant change (neither a rebound nor a further decrease) in these cortical areas up to 20 weeks postlesion. It remains to be decided whether the slight and non-significant rebound in AChE-positive fiber density observed in cortical areas Fr1 and HL at 20 weeks is due to compensatory mechanisms from cholinergic nuclei of basal forebrain areas other than the nBM. Compensatory changes in the cortical cholinergic innervation from surviving neurons following the unilateral immunolesion of the horizontal diagonal band of Broca have been documented (Hartonian and de Lacalle, 2005). Selective immunolesion of cholinergic neurons by the intraventricular injection of 192 IgG-saporin could also result in long-term changes of other neurotransmitter systems (Severino et al., 2007) that could, in turn, influence the outcome of such compensatory mechanisms.

For a clearer understanding of the neurodegenerative processes that follow the destruction of the ascending cholinergic pathway in general, and of the occurrence of any compensatory mechanisms potentially involved in the regenerative processes in particular, 
specific lesions of the cholinergic neurons in the medial septum and the vertical and horizontal limbs of the diagonal band of Broca should additionally be investigated, as should the results after even longer survival times. Moreover, recent advances in technologies related to in vivo imaging in small animals (e.g., PET) for the quantification of amyloid plaques or certain cholinergic biomarkers will inevitably led to a better understanding of the development of the cholinergic hypofunction (Manook et al., 2012; Parent et al., 2012).

\section{Conflict of interest}

Neither the authors nor the institutions with which they are affiliated have any competing interest in the subject or findings of this study.

\section{Acknowledgements}

This work was supported by program project grants to the University of Szeged from the Ministry of National Resources (TÁMOP 4.2.1.B-09/1/KONV-2010-0005, TÁMOP 4.2.2.A-11/1/KONV-20120052) through the European Union Cohesion Fund. The funders had no role in the study design, the data collection and analysis, the decision to publish, or the preparation of the manuscript. The authors thank Mrs. Susan Ambrus and Mrs. Olga Daranyi for excellent technical help.

\section{References}

Abdulla, F.A., Calaminici, M., Gray, J.A., Sinden, J.D., Stephenson, J.D., 1997. Changes in the sensitivity of frontal cortical neurones to acetylcholine after unilateral lesion of the nucleus basalis with alpha-amino-3-OH-4-isoxozole propionic acid (AMPA): effects of basal forebrain transplants into neocortex. Brain Research Bulletin 42, 169-186.

Baxter, M.G., Chiba, A.A., 1999. Cognitive functions of the basal forebrain. Current Opinion in Neurobiology $9,178-183$.

Berger-Sweeney, J., Heckers, S., Mesulam, M.M., Wiley, R.G., Lappi, D.A., Sharma, M., 1994. Differential effects on spatial navigation of immunotoxin-induced cholinergic lesions of the medial septal area and nucleus basalis magnocellularis. Journal of Neuroscience 14, 4507-4519.

Berger-Sweeney, J., Stearns, N.A., Murg, S.L., Floerke-Nashner, L.R., Lappi, D.A., Baxter, M.G., 2001. Selective immunolesions of cholinergic neurons in mice: effects on neuroanatomy, neurochemistry, and behavior. Journal of Neuroscience 21, 8164-8173.

Book, A.A., Wiley, R.G., Schweitzer, J.B., 1994. 192 IgG-saporin: I. Specific lethality for cholinergic neurons in the basal forebrain of the rat. Journal of Neuropathology and Experimental Neurology 53, 95-102.

Brooks, S.P., Jones, L., Dunnett, S.B., 2012. Comparative analysis of pathology and behavioural phenotypes in mouse models of Huntington's disease. Brain Research Bulletin 2012 (88), 81-93.

Butcher, L.L., 1995. Cholinergic neurons and networks. In: Paxinos, G. (Ed.), The Rat Nervous System, 2nd ed. Academic Press, San Diego, pp. 1003-1015.

Butcher, L.L., Woolf, N.J., 1984. Histochemical distribution of acetylcholinesterase in the central nervous system: clues to the localization of cholinergic neurons. In: Björklund, A., Hökfelt, T., Kuhar, M.J. (Eds.), Handbook of Chemical Neuroanatomy, Vol. 3, Classical Neurotransmitters and Transmitter Receptors in the CNS. Elsevier, Amsterdam, pp. 1-50.

Cuello, A.C., Bruno, M.A., Allard, S., Leon, W., Iulita, M.F., 2010. Cholinergic involvement in Alzheimer's disease. A link with NGF maturation and degradation. Journal of Molecular Neuroscience 40, 230-523.

Cuello, A.C., Pioro, E.P., Ribeiro-da-Silva, A., 1990. Cellular and subcellular localization of nerve growth factor receptor-like immunoreactivity in the rat CNS. Neurochemistry International 17, 205-213.

Fitz, N.F., Gibbs, R.B., Johnson, D.A., 2008. Selective lesion of septal cholinergic neurons in rats impairs acquisition of a delayed matching to position T-maze task by delaying the shift from a response to a place strategy. Brain Research Bulletin $77,356-360$

Galani, R., Jeltsch, H., Lehmann, O., Bertrand, F., Cassel, J.C., 2002. Effects of 192 IgGsaporin on acetylcholinesterase histochemistry in male and female rats. Brain Research Bulletin 58, 179-186.

Geula, C., Mesulam, M.M., 1989. Cortical cholinergic fibers in aging and Alzheimer's disease: a morphometric study. Neuroscience 33, 469-481.

Hall, A.M., Roberson, E.D., 2012. Mouse models of Alzheimer's disease. Brain Research Bulletin 88, 3-12.

Harati, H., Barbelivien, A., Cosquer, B., Majchrzak, M., Cassel, J.C., 2008. Selective cholinergic lesions in the rat nucleus basalis magnocellularis with limited damage in the medial septum specifically alter attention performance in the five-choice serial reaction time task. Neuroscience 153, 72-83.
Hartonian, I., de Lacalle, S., 2005. Compensatory changes in cortical cholinergic innervation in the rat following an immunotoxic lesion. Restorative Neurology and Neuroscience 23, 87-96.

Henderson, Z., 1989. Acetylcholinesterase on the dendrites of central cholinergic neurons: an electron microscopical study in the ferret. Neuroscience 28, 95-108.

Höhmann, C.F., Coyle, J.T., 1988. Long-term effects of basal forebrain lesions on cholinergic, noradrenergic and serotonergic markers in mouse neocortex. Brain Research Bulletin 21, 13-20.

Johnson, M.V., McKinney, M., Coyle, J.T., 1981. Neocortical cholinergic innervation: a description of extrinsic and intrinsic components in the rat. Experimental Brain Research 43, 159-172.

Kasa, P., 1986. The cholinergic systems in brain and spinal cord. Progress in Neurobiology 26, 211-272.

Kasa, P., Rakonczay, Z., Gulya, K., 1997. The cholinergic system in Alzheimer's disease. Progress in Neurobiology 52, 511-535.

Kilgard, M.P., Merzenich, M.M., 1998. Cortical map reorganization enabled by nucleus basalis activity. Science 279, 1714-1718.

Kim, I., Wilson, R.E., Wellman, C.L., 2005. Aging and cholinergic deafferentation alter GluR1 expression in rat frontal cortex. Neurobiology of Aging 26, 10731081.

Koelle, G.B., Friedenwald, J.A., 1949. A histochemical method for localizing cholinesterase activity. Proceedings of the Society for Experimental Biology and Medicine 70, 617-622.

Leanza, G., Nilsson, O.G., Wiley, R.G., Bjorklund, A., 1995. Selective lesioning of the basal forebrain cholinergic system by intraventricular 192 IgG-saporin: behavioural, biochemical and stereological studies in the rat. European Journal of Neuroscience 7, 329-343.

Lysakowsky, A., Wainer, B.H., Bruce, G., Hersh, L.B., 1989. An atlas of the regional and laminar distribution of choline acetyltransferase immunoreactivity in the rat cerebral cortex. Neuroscience 28, 291-336.

Mallet, P.E., Beninger, R.J., Flesher, S.N., Jhamandas, K., Boegman, R.J., 1995. Nucleus basalis lesions: implication of basoamygdaloid cholinergic pathways in memory. Brain Research Bulletin 36, 51-56.

Manook, A., Yousefi, B.H., Willuweit, A., Platzer, S., Reder, S., Voss, A., Huisman, M., Settles, M., Neff, F., Velden, J., Schoor, M., von der Kammer, H., Wester, H.J., Schwaiger, M., Henriksen, G., Drzezga, A., 2012. Small-animal PET imaging of amyloid-beta plaques with $[11 \mathrm{C}] \mathrm{PiB}$ and its multi-modal validation in an APP/PS1 mouse model of Alzheimer's disease. PLoS ONE 7, e31310.

Martucciello, G., Favre, A., Torre, M., Pini Prato, A., Jasonni, V., 2001. A new rapid acetylcholinesterase histochemical method for the intraoperative diagnosis of Hirschsprung's disease and intestinal neuronal dysplasia. European Journal of Pediatric Surgery 11, 300-304.

Mesulam, M.M., Mufson, E.J., Wainer, B.H., Levey, A.I., 1983. Central cholinergic pathways in the rat: an overview based on an alternative nomenclature (Ch1-Ch6). Neuroscience 10, 1185-1201.

Mohapel, P., Leanza, G., Kokaia, M., Lindvall, O., 2005. Forebrain acetylcholine regulates adult hippocampal neurogenesis and learning. Neurobiology of Aging 26, 939-946.

Mufson, E.J., Counts, S.E., Perez, S.E., Ginsberg, S.D., 2008. Cholinergic system during the progression of Alzheimer's disease: therapeutic implications. Expert Review of Neurotherapeutics 8, 1703-1718.

Nag, N., Baxter, M.G., Berger-Sweeney, J.E., 2009. Efficacy of a murine-p75-saporin immunotoxin for selective lesions of basal forebrain cholinergic neurons in mice. Neuroscience Letters 452, 247-251.

Parent, M., Bedard, M.A., Aliaga, A., Soucy, J.P., Landry St-Pierre, E., Cyr, M., Kostikov, A., Schirrmacher, E., Massarweh, G., Rosa-Neto, P., 2012. PET imaging of cholinergic deficits in rats using [18F]fluoroethoxybenzovesamicol ([18F]FEOBV). Neuroimage 62, 555-561.

Paxinos, G., Watson, C., 2007. The Rat Brain in Stereotaxic Coordinates, 6th ed. Academic Press/Elsevier, Amsterdam.

Perry, T., Hodges, H., Gray, J.A., 2001. Behavioural, histological and immunocytochemical consequences following 192 IgG-saporin immunolesions of the basal forebrain cholinergic system. Brain Research Bulletin 54, 29-48.

Pizzo, D.P., Waite, J.J., Thal, L.J., Winkler, J., 1999. Intraparenchymal infusions of 192 IgG-saporin: development of a method for selective and discrete lesioning of cholinergic basal forebrain nuclei. Journal of Neuroscience Methods 91, 9-19.

Ridley, R.M., Baker, H.F., Leow-Dyke, A., Cummings, R.M., 2005. Further analysis of the effects of immunotoxic lesions of the basal nucleus of Meynert reveals substantial impairment on visual discrimination learning in monkeys. Brain Research Bulletin 65, 433-442.

Rossner, S., Schliebs, R., Bigl, V., 1995a. 192IgG-saporin-induced immunotoxic lesions of cholinergic basal forebrain system differentially affect glutamatergic and GABAergic markers in cortical rat brain regions. Brain Research 696, 165-176.

Rossner, S., Schliebs, R., Härtig, W., Bigl, V., 1995b. 192IgG-saporin-induced selective lesion of cholinergic basal forebrain system: neurochemical effects on cholinergic neurotransmission in rat cerebral cortex and hippocampus. Brain Research Bulletin 38, 371-381.

Satoh, K., Armstrong, D.M., Fibiger, H.C., 1983. A comparison of the distribution of central cholinergic neurons as demonstrated by acetylcholinesterase pharmacohistochemistry and choline acetyltransferase immunohistochemistry. Brain Research Bulletin 11, 693-720.

Severino, M., Pedersen, A.F., Trajkovska, V., Christensen, E., Lohals, R., Veng, L.M., Knudsen, G.M., Aznar, S., 2007. Selective immunolesion of cholinergic neurons leads to long-term changes in 5-HT2A receptor levels in hippocampus and frontal cortex. Neuroscience Letters 428, 47-51. 
Stichel, C.C., Singer, W., 1987. Quantitative analysis of the choline acetyltransferaseimmunoreactive axonal network in the cat primary visual cortex: II. Pre- and postnatal development. Journal of Comparative Neurology 258, 99-111.

Walsh, T.J., Kelly, R.M., Dougherty, K.D., Stackman, R.W., Wiley, R.G., Kutscher, C.L., 1995. Behavioral and neurobiological alterations induced by the immunotoxin 192-IgG-saporin: cholinergic and non-cholinergic effects following i.c.v. injection. Brain Research 702, 233-245.

Wenk, G.L., Stoehr, J.D., Quintana, G., Mobley, S., Wiley, R.G., 1994. Behavioral, biochemical, histological, and electrophysiological effects of 192 IgG-saporin injections into the basal forebrain of rats. The Journal of Neuroscience 14, 5986-5995.
Wiley, R.G., Berbos, T.G., Deckwerth, T.L., Johnson Jr., E.M., Lappi, D.A., 1995. Destruction of the cholinergic basal forebrain using immunotoxin to rat NGF receptor: modeling the cholinergic degeneration of Alzheimer's disease. Journal of the Neurological Sciences 128, 157-166.

Wiley, R.G., Oeltmann, T.N., Lappi, D.A., 1991. Immunolesioning: selective destruction of neurons using immunotoxin to rat NGF receptor. Brain Research 562 149-153.

Wrenn, C.C., Wiley, R.G., 1998. The behavioral functions of the cholinergic basa forebrain: lessons from $192 \mathrm{IgG}$-saporin. International Journal of Developmental Neuroscience 16, 595-602.

Zilles, K., Wree, A., 1995. Cortex: areal and laminar structure. In: Paxinos, G. (Ed.), The Rat Nervous System, 2nd ed. Academic Press, San Diego, pp. 649-685. 